\title{
DEBER DE VERACIDAD DE LAS PARTES EN EL PROCESO CIVIL: ¿UNA EXIGENCIA MÁS ALLÁ DE SU CONSAGRACIÓN LEGAL? ANÁLISIS A PROPÓSITO DEL SISTEMA PROCESAL CIVIL URUGUAYO
}

\author{
María Cecilia Barnech Cuervo \\ Universidad Católica del Uruguay, Montevideo, Uruguay \\ Contacto:mbarnech@hotmail.com
}

Recibido: 26 de agosto de 2020 Aprobado: 29 de diciembre de 2020

Para citar este artículo:

Barnech Cuervo, M. C. (2021).

"Deber de veracidad de las partes en el proceso civil: ¿Una exigencia más allá de su consagración legal? Análisis a propósito del sistema procesal civil uruguayo". Prudentia Iuris, N. 91, pp. 45-72 DOI: https://doi.org/10.46553/prudentia.91.2021.pp.45-72

Resumen: En la dogmática procesal civil, la veracidad, particularmente como deber impuesto a las partes, resulta altamente controvertida. A pesar de ello, el sistema procesal civil uruguayo la reconoce especialmente. Este cuestionamiento y los dilemas que la sociedad contemporánea enfrenta nos interpelan acerca del rol que el Derecho juega en esta realidad. La presente investigación reseña brevemente el estado de la cuestión para luego analizar la pertinencia y legitimidad en la normativa uruguaya. Finalmente, desde una mirada más filosófica, se justificará, además, por qué esta exigencia se mantiene como tal, aun sin estar consagrada legalmente. Entendiendo los deberes como forma de protección de los derechos y la búsqueda de la verdad como inherente a la condición humana, el deber de veracidad de las partes en el proceso -más allá de su consagración jurídica expresa- no solo no encontraría grandes objeciones, sino que aparecería como inexcusable.

Palabras clave: Proceso, Veracidad, Deberes, Filosofía, Condición humana. 


\title{
Duty of Veracity of the Parties in the Civil Process: A Requirement Beyond its Legal Consecration? Analysis in Apropos of the Uruguayan Civil Procedure System
}

\begin{abstract}
In civil procedure doctrine, veracity, particularly as a duty imposed on the parties, is highly questioned. Nevertheless, the Uruguayan system especially recognizes it. This dispute and the dilemmas that contemporary society faces, challenge us about the role that law plays in this situation. This research briefly reviews the state of the issue in to later analyze the relevance and legitimacy of the Uruguayan normative. Finally, why this requirement remains as such, beyond its normative consecration will also be justified from a philosophical perspective. Understanding duties as a form of protection of rights and the search for truth as inherent to the human condition, the duty of veracity of the parties in the process -beyond its express legal consecration- not only would not encounter major objections, but which would appear inexcusable.
\end{abstract}

Keywords: Process, Veracity, Duties, Philosophy, Human nature.

\section{Dovere di verità delle parti nel processo civile: un requisito oltre la sua consacrazione normativa? Analisi in relazione al sistema processuale civile uruguaiano}

Sommario: Nella dottrina processuale civile, la verità, in particolare come dovere delle parti, è fortemente messa in discussione. Il sistema processuale civile uruguaiano lo riconosce specificamente. Tale questione e i dilemmi che la società contemporanea deve affrontare ci sfidano sul ruolo che il diritto gioca in questa realtà. Questa indagine esamina brevemente lo stato della questione nella dottrina specializzata per poi analizzare la rilevanza e la legittimità delle normative uruguaiane. Infine, da un punto di vista filosofico, sarà anche giustificato il motivo per cui tale requisito rimane tale, anche senza essere legalmente sancito. Comprendere i doveri come una forma di protezione dei diritti e la ricerca della verità come inerente alla condizione umana, il dovere di verità delle parti nel processo -al di là della sua espres- 
sa consacrazione legale- non solo non incontrerebbe obiezioni importanti, ma che sembrerebbe imperdonabile.

Parole chiave: Processo, Doveri, Veritá, Pilosofia, Condizione umana.

\section{La veracidad en la dogmática procesal civil}

"Veritas, atis (de verus): verdad, lo verdadero; sinceridad, franqueza"1.

Según el Diccionario de la Real Academia Española, la veracidad es "cualidad de veraz", "que dice, usa y profesa siempre la verdad"2. La veracidad se relaciona con la honestidad, la franqueza, lo recto.

En el ámbito jurídico, surgen conceptos afines: derecho a la verdad ${ }^{3}$, deber de veracidad, deberes de coherencia y completitud. Estos deberes procesales, por su parte, han sido ampliamente debatidos y de difícil resolución, en marco del principio de buena fe procesal ${ }^{4}$.

Taruffo, desde su visión epistémica del proceso, y aun entendiendo que la verdad cuenta y es alcanzable, considera que ello no habilita a imponer a las partes un deber de colaborar activamente en la determinación de la verdad de los hechos. Justamente, la actividad de estos (como sujetos interesados) no cumple esa función epistémica que quedará para el juez ${ }^{5}$.

1 Diccionario manual latino-español, español-latino (1987). Barcelona. Sopena.

2 Diccionario de la lengua española (1992). Madrid. Espasa-Calpe.

3 Cfr. González Salzberg, D. A. (2008). "El derecho a la verdad en situaciones de postconflicto bélico de carácter no internacional". International Law: Revista Colombiana de Derecho Internacional, Nro. 12, 450.

También en Resoluciones Nros. 66/2005, 12/2011 y 12/2012. Gozaíni, O. (2017). El debido proceso. Estándares de la Corte Interamericana de Derechos Humanos. Buenos Aires. RubinzalCulzoni, Vol. 1, 83 y 126.

4 Cfr. Abal Oliú, A. (2014). "La verdad y el proceso jurisdiccional en Uruguay". En I Seminario Internacional de Derecho Procesal: Dilemas sobre la verdad en el proceso judicial (Colección de Investigaciones en Derecho Nro. 2). Medellín. Universidad Pontificia Bolivariana, 187-223.

5 "En resumen, a lo sumo se invita o se obliga a las partes a evitar conductas obstructivas [...], pero todo esto no equivale a imponer a las partes un deber de colaborar activamente en la determinación de la verdad de los hechos. [...] las actuaciones de las partes no pueden quedar comprendidas en el ámbito de la dimensión epistémica del proceso". Taruffo, M. (2010). Simplemente la verdad. El juez y la construcción de los hechos. Madrid. Marcial Pons, 192-196. Taruffo, M. (2013). "Verdad, prueba y motivación en la decisión sobre los hechos". Cuadernos de Divulgación de la Justicia Electoral, Nro. 20, 18-30. 
Desde visiones ideológicas más liberales, Montero Aroca vincula el surgimiento "no casual" del principio de buena fe procesal y sus correlativos deberes con los códigos procesales de URSS y la Alemania fascista y así aboga por su desconocimiento ${ }^{6}$.

En Latinoamérica, en una visión de proceso meramente dispositivo o acusatorio, Alvarado Velloso plantea -bajo los postulados del "garantismo procesal"- que el proceso es un verdadero método de debate en que la verdad y la justicia no interesan primordialmente al Derecho. Aunque igualmente incluye el principio de "moralidad" dentro del catálogo de principios informadores del proceso (en distinción a las reglas), le otorga un alcance limitado y cuestiona duramente la imposición de veracidad ${ }^{7}$.

Coloma, si bien reconoce que dependerá de cada sistema procesal, considera que, en principio, no hay restricciones para la clase de historias que pudieren ser presentadas y será el juez quien tomará la decisión sobre una serie de reglas que delimitan lo que debe y lo que no debe ser aceptado. Alcanzará con que se privilegien aquellas historias que puedan llegar a considerarse como verdaderas y se eviten las que aparezcan como disparatadas, pues estas definitivamente no favorecerán a sus intereses ${ }^{8}$.

Estas posturas son calificadas por Picó i Junoy como "revisionistas", en tanto, o bien no reconocen la buena fe procesal como principio rector del proceso, o no le otorgan la debida relevancia o alcance, o la observan con

6 Montero Aroca, J. (2006). "El proceso civil llamado 'social' como instrumento de 'justicia' autoritaria”. En J. Montero Aroca (Coord.). Proceso civil e ideología: un prefacio, una sentencia, dos cartas y quince ensayos. Valencia. Tirant Lo Blanch, 130-165. Cfr., también, Montero Aroca, J. (2011). "Sobre el mito autoritario de la buena fe procesal". En J. Montero Aroca (Coord.). Proceso civil e ideología. Madrid. Tirant Lo Blanch, 292-350. Cipriani, F. (2006). "El abogado y la verdad". En J. Montero Aroca (Coord.). Proceso civil e ideología: un prefacio, una sentencia, dos cartas y quince ensayos. Valencia. Tirant Lo Blanch, 283-294. Cfr., también: Cipriani, F. (2007). "El autoritarismo procesal (y las pruebas documentales)". Revista Ius et Praxis, año 13, Nro. 2, 44-55.

7 Alvarado Velloso, A. (2014). "Proceso y Verdad". En I Seminario Internacional de Derecho Procesal: Dilemas sobre la verdad en el proceso judicial (Colección de Investigaciones en Derecho, Nro. 2). Medellín. Universidad Pontificia Bolivariana, 128-129. Cfr. también: Alvarado Velloso, A. (2014). "La imparcialidad judicial y el debido proceso (la función del juez en el proceso civil)". Revista Ratio Juris, Vol. 9, Nro. 18, 207-235. Calvinho, G. (2010). "Los Derechos Humanos en la teoría del proceso". En G. Águila Grados; A. Calderón Sumarriva; G. Calvinho y R. M. González. El Derecho Procesal del siglo XXI. Lima. San Marcos, 37-76. González, R. M. (2010). "Proceso, república y democracia: algunas claves para constitucionalizar el proceso". En G. Águila Grados; A. Calderón Sumarriva; G. Calvinho y R. M. González. El Derecho Procesal del siglo XXI. Lima. San Marcos, 76-116.

8 Coloma Correa, R. (2006). "Vamos a contar mentiras, tralará..., o de límites a los dichos de los abogados”. Revista de Derecho, Vol. XIX, Nro. 2, 27-52. 
desconfianza ${ }^{9}$. Entiende que el deber de veracidad de las partes "comporta la necesidad de no alegar como hechos existentes los que les constan como inexistentes, y viceversa, esto es, la necesidad de no alegar como desconocidos aquellos hechos cuya existencia conocen". Ello no implica desconocer ni desproteger la libertad de las alegaciones fácticas iniciales, pero se sobreentiende que ese ejercicio encuentra límites y que uno de ellos es, precisamente, la veracidad ${ }^{10}$.

Simon Caureo define esta exigencia como el deber de decir la verdad de acuerdo con el conocimiento de cada uno, de ser fiel al conocimiento subjetivo de los hechos. Tiene como correlato la prohibición de decir mentiras, de afirmar conscientemente hechos falsos. Es decir, opera como un mecanismo deontológico de corrección y control del poder de apego de las partes $^{11}$.

En la dogmática argentina especializada, Barberio y García Solá reconocen este deber como manifestación necesaria del principio de moralidad ${ }^{12}$. Heñin explica, además, que el principio dispositivo tampoco es un obstáculo para imponer esta conducta debida a las partes; es más, la mentira no puede ser tolerada en el proceso, ni siquiera con la justificación de que es la parte quien incurre en ella ${ }^{13}$.

9 Picó i Junoy, J. (2012). "El Derecho Procesal entre el garantismo y la eficacia: un debate mal planteado". Urbe et Ius: Revista de Opinión Jurídica, Nro. 38, 50-56. Cfr. también: Picó i Junoy, J. (2002). "Los principios del nuevo proceso civil español". En XVIII Jornadas Iberoamericanas de Derecho Procesal, Jornadas Uruguayas de Derecho Procesal: en homenaje a la escuela procesalista uruguaya (185-212). Montevideo. Fundación de Cultura Universitaria. Peyrano, J. W. (2011). "El cambio de paradigmas en materia procesal civil". En J. W. Peyrano (Director). Principios procesales. Tomo I. Buenos Aires. Rubinzal-Culzoni, 131-139.

10 Picó i Junoy, J. (2013). El principio de la buena fe procesal. Madrid. José María Bosch Editor, 148 y 153. Sobre el debate entre los denominados "revisionistas" y "negacionistas", cfr.: Montero Aroca, J. (Coord.) (2006). Proceso civil e ideología: un prefacio, una sentencia, dos cartas y quince ensayos. Valencia. Tirant Lo Blanch.

11 Simon Caureo, E. (2018). "Il dovere di verità e completezza nel processo civile (Duty of Truthful Disclosure and Duty of Completeness in civil procedure, traducción libre)". Civil Procedure Review, Vol. 9, Nro. 1, 27-42. Cfr. también: Simon Caureo, E. (2017). "Introduzione al dovere di verità e completezza nel processo civile”. En Grisi G. y Salvi C. (Eds.). A propósito del diritto post-moderno. Atti Seminario Leonessa. Roma. Roma TrE-Press, 91-104.

12 Barberio, S. y García Solá, M. (2011). "Lineamientos del principio de moralidad". En J. W. Peyrano (Director). Principios procesales. Tomo I. Buenos Aires. Rubinzal-Culzoni, 730-731. Cfr. también: Peyrano, J. W. (2010). "Acerca de los 'ismos' en materia procesal civil". THËMIS-Revista de Derecho, Nro. 58, 23-27. Peyrano, J. W. (2006). "El abuso procesal recursivo o situación de recurso ad infinitum". Ius et Veritas, Nro. 33, 195-197.

13 Heñin, F. A. (2011). "El principio de moralidad en el proceso civil”. En J. W. Peyrano (Director). Principios procesales. Tomo I. Buenos Aires. Rubinzal-Culzoni, 745. Cfr. también: Balestro Faure, M. (2011). "El principio que prohíbe el abuso de los Derechos Procesales”. En J. W. Peyrano (Director). Principios procesales. Tomo I. Buenos Aires. Rubinzal-Culzoni, 870. 


\title{
M. CECILIA BARNECH CUERVO
}

Se puede distinguir del deber de integridad o completitud en que este impone además no omitir, a sabiendas, información o hechos relevantes para el proceso. También se diferencia del deber de coherencia porque este impone una conducta alegacional coherente a lo largo del proceso y, por tanto, se relaciona con la teoría de los actos propios en el ámbito procesal ${ }^{14}$.

En conclusión, la dogmática no ha resuelto la problemática. Conviven aún dos sectores que conceptualizan el Derecho Procesal, el proceso y los deberes desde ángulos aparentemente antagónicos.

Sin perjuicio, coincidimos con Peyrano -más allá de su postura puntual al respecto ya referida- en que no resulta útil y es hasta inconveniente la polarización de las visiones que, al final del día, solo conspiran contra el debate dogmático fructífero ${ }^{15}$.

\section{Deber de veracidad en el sistema procesal civil uruguayo}

\author{
"Hay mentiras que pueden ser incluso de cortesía, poéticas, \\ que no tienen que escandalizar ni perturbar. \\ Muy al contrario, algunas se encuentran ya integradas en el juego social. \\ Lo importante de la mentira es el contexto y a quién se miente. \\ Pero también hay mentiras que son graves y dañinas \\ para la mutua confianza de una sociedad. \\ Son las que entran en el contexto oficial [...]”16.
}

El proceso civil uruguayo, en forma general, está regulado por la Constitución y las normas del Derecho Internacional de los Derechos Hu-

14 Simon Caureo, E. (2018). Ob. cit., 27-42. La dogmática procesal no es conteste respecto de la identidad o relación entre el deber de veracidad, el deber de completitud o coherencia y la teoría de los actos propios, en lo que no nos detenemos en el presente trabajo, ya que no se pretende una profundización estrictamente procesal. Cfr.: Canteros, F. (2017). "La doctrina de los actos propios y la mala fe procesal". Revista da Esmal, Nro. 6, 95-104. Ordoqui Castilla, G. (2009). Abuso de derecho. En civil, comercial, procesal, laboral y administrativo. Montevideo. Universidad Católica del Uruguay, 567-582. Barberio, S. y García Solá, M. (2011). "Lineamientos del principio de moralidad". En J. W. Peyrano (Director). Principios procesales. Tomo I, citas de jurisprudencia argentina. Buenos Aires. Rubinzal-Culzoni, 205. Eguren, M. C. (2011). "El principio de eventualidad procesal: los alcances de una autocontradicción permitida". En J. W. Peyrano (Director). Principios procesales. Tomo I. Buenos Aires. Rubinzal-Culzoni, 453-478. Picó i Junoy, J. (2013). El principio de la buena fe procesal. Madrid, José María Bosch Editor, 156. Gradi, M. (2018). L'obbligo di verità delle parti. Torino. G. Giappichelli Editore, XXIX (presentazione) y 759.

15 Peyrano, J. W. (2010). Ob. cit., 23-27.

16 Savater, F. (2004). Los diez mandamientos en el siglo XXI. Tradición y actualidad del legado de Moisés. Barcelona. Random House Mondadori, 54. 
manos ${ }^{17}$. Por su parte, el CGP (Ley $\mathrm{N}^{\circ} 15.982$ y sus modificativas y, en particular, la Ley $\mathrm{N}^{\circ} 19.090$ ) regula específicamente los procesos civiles y fue inspirado, en gran medida, por el Código Procesal Civil Modelo para Iberoamérica (CPCM) presentado por el Instituto Iberoamericano de Derecho Procesal.

La veracidad, respecto de las partes, está explícita y particularmente consagrada en dos disposiciones, los artículos $5^{\circ}$ y 63 del CGP, que en ambos casos reproducen el CPCM ${ }^{18}$.

El artículo 63 exige que los actos procesales sean lícitos, pertinentes y útiles; que se realicen con veracidad y buena fe. Refiere a los actos procesales en general, lo que, en el caso de las partes, se materializa especialmente en los actos de proposición y, eventualmente, en su declaración. Además, en la vigencia de la Ley $\mathrm{N}^{\circ} 15.982$, ley original del CGP, se consagraban la buena fe y lealtad procesal en el artículo $5^{\circ}$.

Con la reforma introducida por la Ley $\mathrm{N}^{\circ} 19.090$ se produce una modificación a esta disposición, con lo cual se incorpora el deber específico, a todos los sujetos, de actuar con veracidad. Sin perjuicio, Véscovi, por ejemplo, con anterioridad (simplemente con la vigencia del artículo 63) ya reconocía su existencia y pertinencia, en cuanto los requisitos de veracidad y buena fe importan una exigencia ética respecto de toda la actividad procesal y de todos los sujetos intervinientes ${ }^{19}$.

Además, se incorporó la colaboración procesal, pero su alcance fue fuertemente discutido. El proyecto propuesto por la Suprema Corte de Justicia (SCJ) agregaba el deber de veracidad y colaboración procesal para la realización de todos los actos procesales, sin limitaciones o, por lo menos, sin remisión a ninguna otra disposición.

17 Artículos 7, 12-28, 72 y 332 de la Constitución y artículos 8 y 25 de la Convención Americana sobre Derechos Humanos (CADH). Cfr. Landoni, Á. (Director) (2002). Código General del Proceso comentado, anotado, con jurisprudencia. Montevideo. BdeF, Vol. 1, 10-13.

18 Cfr. Exposición de motivos del Código General del Proceso, Código General del Proceso, versión anotada y concordada por Biurrun Berneron R. y Uriarte Audi G. (2013). Montevideo. Fundación de Cultura Universitaria, 10. Pereira Campos, S. (2016). "Moralidad, veracidad y colaboración: su incidencia en el proceso civil contemporáneo. El Código Procesal Civil Modelo para Iberoamérica y la experiencia de Código General del Proceso uruguayo". En Modernización de la justicia civil. Montevideo. Universidad de Montevideo, 406-446. Pereira Campos, S. (2009). "Los procesos civiles por audiencias en Uruguay. 20 años de aplicación exitosa del Código Procesal Civil Modelo para Iberoamérica”. Revista Internacional de Estudios de Derecho Procesal y Arbitraje, Nro. 2, 5.

19 Véscovi, E. (Director) (1992). Código General del Proceso. Tomo I. Montevideo. Ábaco, $130-134$ y $282-283$. 


\section{CECILIA BARNECH CUERVO}

Luego de las discusiones parlamentarias ${ }^{20}$, finalmente se aprobó el artículo con la remisión expresa al artículo 142, en que se dispone que las partes tienen el deber de prestar la colaboración del buen litigante para la efectiva y adecuada producción de la prueba.

Esta puja encuentra explicación en dos visiones relativamente antagónicas, que se vinculan con la problemática planteada en el apartado anterior, "La veracidad en la dogmática procesal civil". Van Rompaey ha sostenido que la colaboración procesal incluye la aportación, por parte de las partes, de toda la información y los elementos de convicción disponibles ${ }^{21}$.

Para Landoni, este actuar con veracidad se traduce en brindar información veraz y completa de los hechos, sin retaceos, es decir, que incluye las exigencias de completitud y coherencia y aun de aportación completa de prueba a disposición ${ }^{22}$.

Para Cal Laggiard, este deber no resulta ajeno al sistema porque es coincidente con la regulación de la valoración de la conducta procesal de las partes dispuesta por el artículo 688 del Código Civil ${ }^{23}$.

Abal Oliú advierte que solo se les impone la colaboración procesal a las partes en la producción de la prueba y "no en cualquier otra actividad procesal" 24 .

A pesar de estas diferencias, el CGP incluyó la colaboración procesal y la veracidad como un deber impuesto a las partes. En consecuencia, parece insoslayable reconocer que se consolidó, en palabras de Landoni, una "tendencia a la moralización del proceso y su humanización” 25 .

20 Cfr. Valentín, G. (2014). La reforma del Código General del Proceso. Montevideo. Fundación de Cultura Universitaria, 11-15. Abal Oliú, A. (2013). "El principio de buena fe procesal a partir del nuevo texto del art. $5^{\circ}$ del CGP”. Revista CADE. Doctrina y Jurisprudencia, Nro. 24, 5-10. Abal Oliú, A. (2014). Ob. cit., 204-207.

21 Van Rompaey, L. (1995). "La teoría de las cargas probatorias dinámicas en el Derecho Procesal uruguayo". La Justicia Uruguaya. Tomo 111, 447-453. También, Pereira Campos, S. (2013). "La reforma de la justicia civil en América Latina: una política pública ineludible". Revista Derecho \& Sociedad, Nro. 41, 251-256. Baluga Bello, C. (2015). "La aplicación del principio de buena fe en la audiencia preliminar". En XVIII Jornadas de Derecho Procesal. Montevideo. Fundación de Cultura Universitaria, 19-32.

22 Landoni, Á. (2014). "Las modificaciones introducidas al Código General del Proceso por la Ley $\mathrm{N}^{\circ}$ 19.090. Sentido general de la reforma". En Curso sobre la reforma del Código General del Proceso (Ley $N^{\circ}$ 19.090). Montevideo. La Ley, 40.

23 Cal Laggiard, M. (2013). "Primeras lecturas de la reforma del CGP". Revista de Derecho de la Universidad de Montevideo, Nro. 24, 25.

24 Abal Oliú, A. (2013). Ob. cit., 5-10. Valentín, G. (2014). La reforma del Código General del Proceso. Montevideo. Fundación de Cultura Universitaria, 11-16.

25 Landoni, Á. (2014). Ob. cit., 30-33. 


\section{La veracidad, ¿puede entenderse como un deber jurídico impuesto legítimamente a las partes en el proceso civil uruguayo?}

\subsection{Respuesta desde la historia}

"E es llamada esta jura Juramentum calumnia, que quiere tanto dezir, como jura que fazen los ornes que andarán verdaderamente en el pleyto, e sin engaño. E esta jura es llamada otrosi en algunos logares Manquadra, porque ha en ella cinco cosas, que deue jurar también el demandador, como el demandado. [...]

La segunda es, que quantas vegadas le preguntaren en juyzio por razon de aquella demanda; que siempre dira, lo que entendiere que es verdad, non mezclando y ninguna mentira, nin ningún engaño, nin ninguna falsedad, a sabiendas"26.

No se pretende en este apartado fundamentar históricamente el reconocimiento o la consagración de este deber de veracidad, sino simplemente reconocer puntos de contacto en algunas regulaciones procesales no vigentes vinculadas al sistema procesal uruguayo ${ }^{27}$.

Podemos afirmar, en términos amplios, que el sistema procesal uruguayo encuentra antecedentes, en menor o mayor medida, en el proceso común (romano-canónico) del Derecho indiano y, más cercanamente, en la Ley de Enjuiciamiento Civil de $1855^{28}$.

Respecto a la conducta proba o de buena fe, con carácter general, Valiño recuerda que el Derecho romano se preocupó por el comportamiento simulado en el proceso, al requerir una serie de garantías y juramentos. Por ejemplo, en el caso de la cautio iudicatum solvi, la palabra tiene valor en

26 Siete Partidas de Alfonso el Sabio, III, 11, 23.

27 Sin perjuicio, coincidimos en que "no es correcto interpretar linealmente la evolución del Derecho y considerar el actual como una derivación lógica, como germinatio del precedente [...]. Lo que no excluye necesariamente la aparición de líneas que, en cierto modo, conectan el pasado al presente. En cierto modo: porque son paralelas, no desvelan explícitamente el itinerario, y de cuando en cuando se evaporan para reaparecer después donde nadie las busca. Indican, con su proceder intermitente, un camino poco previsible y difícilmente descifrable". Caroni, P. (2014). La soledad del historiador del Derecho. Apuntes sobre la conveniencia de una disciplina diferente. Madrid. Dykinson, 191.

28 Cfr. Exposición de motivos del Código General del Proceso, Código General del Proceso, versión anotada y concordada por Biurrun Berneron, R. y Uriarte Audi, G. (2013). Montevideo. Fundación de Cultura Universitaria, 9-13. Couture, E. (2016). Estudios de Derecho Procesal Civil. Tomo 3. Montevideo. La Ley, 236-240. 
cuanto el demandado promete ante fiadores cumplir la sentencia de condena; o, en el caso del iusiurandum calumniae, tanto el actor como el demandado juraban que no demandaban o no se oponían con la única intención de dañar al adversario ${ }^{29}$.

Por otra parte, las Siete Partidas de Alfonso X en el siglo XIII representan un hito como esfuerzo compilador del Derecho en el que la Tercera Partida constituye un verdadero tratado sobre regulación procesal. En ella aparecen varias leyes que regulan la conducta esperada de los sujetos intervinientes en el proceso. Sobre las partes, por ejemplo, encontramos referencias en el Título II, leyes XV y XL De la demanda; en las leyes XIX, XX, XXII De la tenencia de cosa demandada; en la ley XLIII Del demandante que pide de más; y en la ley XLIV Del demandante que pide deuda falsa. La justicia y la verdad no resultan conceptos indiferentes, sino que aparecen como valores protegidos por el proceso ${ }^{30}$.

Respecto al valor de la palabra dada en juicio por los litigantes, en el Título XI, ley XXIII, se regulan los juramentos, especialmente el de calumnia o "manquadra", por el cual aquellos juraban ante el juez que no procederían con engaño y alegarían lo que "entendieran por verdad".

En el Derecho indiano, la ley V de la Real Cédula de Aranjuez de 1794 dispone que "en los juicios se ha de proceder siempre a estilo llano, verdad sabida y buena fe guardada" 31 .

En cuanto al ordenamiento patrio, Simón encuentra como antecedente a este instituto los artículos 327, 466 y 679 del Código de Procedimiento Civil, en los que ya está presente la búsqueda de la verdad en la actividad probatoria, la falsedad como causal de nulidad y la imposición de costas y costos en caso de conducta maliciosa o de clara ligereza.

En síntesis, podemos advertir que la veracidad, en sentido amplio, se encontraba presente en textos antecedentes -aunque con oscilaciones $^{32}-\mathrm{y}$

29 Valiño Arcos, A. (2002). "Algunos aspectos relacionados con la imposición de costas en el proceso civil en el Derecho Comparado". Revista Facultad de Derecho, Nro. 21, 251-267. Cfr. también: Gradi, M. (2018). L'obbligo di verità delle parti. Torino. G. Giappichelli Editore, 99-144. No se desconoce la negación histórico-teórica del deber de veracidad. Cfr. Arcaria, F. (2019). "Il 'dovere di verità'. Contributo alla comparazione tra la deontologia forense italiana e l'esperienza giuridica romana". Teoria e Storia del Diritto Privato, Nro. XII, 1-100.

30 Cfr. Barnech Cuervo, M. C. (2019). Siete Partidas de Alfonso X: ¿Puede advertirse una exigencia de conducta proba para los sujetos intervinientes en el pleito en la regulación procesal de la Tercera Partida? [trabajo presentado en el marco del Doctorado de Ciencias Jurídicas, Universidad Católica Argentina].

31 "Real Cédula de Erección del Consulado de Buenos Ayres expedida en Aranjuez a XXX de enero de MDCCXCI". Madrid. En la Oficina de Benito Cano, Ley V, 5.

32 Sin perjuicio, debe reconocerse que las regulaciones españolas (Ley de Enjuiciamiento Civil española de 1855 y 1871) no contienen disposiciones en este sentido. Cfr. Couture, E. (2016). Estudios de Derecho Procesal Civil. Tomo III. Montevideo. La Ley, 172. 
se aplicaban sanciones en caso de desvío. Es decir, la veracidad como exigencia de conducta de las partes no es ajena al Derecho.

\title{
3.2. Respuesta desde el pensamiento de Couture
}

\author{
"La búsqueda de la verdad tiene estas cosas. \\ ¿Pero podrá la especie humana proclamar que en su larga \\ y conmovedora aventura sobre la tierra no ha podido aún \\ lograr una justicia inspirada por la verdad?"33.
}

El sistema procesal uruguayo, así como el de los demás países latinoamericanos, está fuertemente inspirado por las ideas de Couture. La evolución de la regulación del proceso en Uruguay encuentra base en sus enseñanzas, por lo que pensar los sistemas procesales latinoamericanos, y especialmente el uruguayo, impone tener presente su perspectiva ${ }^{34}$.

El pensamiento de Couture es muy vasto y profundo, y va más allá del análisis de la regulación particular de la ley procesal. Realiza un planteo crítico sobre el proceso civil y su relación con el pensamiento individualista liberal del siglo XIX, para demostrar que el sistema procesal basado en ese enfoque aparece como insuficiente, que la igualdad formal de las partes y la total autonomía de la voluntad aparecen en crisis. Así, debe darse paso a un "Derecho Procesal de la democracia", superador de las deficiencias del anterior.

Presentando una síntesis de los enfoques existentes a la época de su producción, adhiere a la postura de quienes reconocen un deber de decir verdad con texto expreso y sin texto expreso, con sanciones y sin sanciones, bastando el cúmulo de disposiciones que se hallan en todos los códigos tendientes a reprimir la ligereza, la malicia o el dolo del proceso ${ }^{35}$. Parte de la idea general de que inicialmente existe un principio ínsito que determinaría un deber de las partes de decir la verdad, en tanto "el Derecho no puede ser torcido". Es más, el proceso tiene cierta inherencia de verdad porque es la realización de la justicia y esta no debería basarse en la mentira. Si bien el proceso puede ser visto como un debate dialéctico, tiene como eje central la justicia. Concluye que dicho deber es un deber de conducta humana, más allá del proceso, y que, a posteriori, cada sistema

33 Couture, E. (2016). Ob. cit., 187.

34 Pereira Campos, S. (2016). Ob. cit., 30-85. Cfr., también, Discusiones parlamentarias disponibles en https://parlamento.gub.uy/documentosyleyes/ficha-asunto/36010/tramite.

35 Couture, E. (2016). Ob. cit., 173-175. 
y ley procesal ubicará este imperativo, consagrándolo ya sea como obligación, deber o carga ${ }^{36}$.

En consecuencia, entendemos que todo lo expresado justifica la afirmación de que la veracidad consagrada en la regulación vigente es consistente con el pensamiento de Couture, que es efectivamente su inspirador.

"La noción de espejo comprende la idea de reflejo. Y esta última puede aplicarse tanto a Couture [...]. Sus vidas son los ecos de tiempos pasados. Sintetizan una época con repercusiones presentes. Volver sobre sus pasos ayuda a entender los dilemas de hoy. La historia como construcción permanente brinda explicaciones del presente con razones del pasado que se transforman al relacionarse con una diversidad que las condiciona" ${ }^{37}$.

\subsection{Respuesta desde los conceptos de proceso, debido proceso y tutela jurisdiccional efectiva}

Martini: "Quisiera ahora hacer una pregunta al profesor Zagrebelsky [sobre...] la imposibilidad de definir la justicia. No entiendo cómo no se pueda reconocer que una cosa es el anhelo de justicia, inseparable de toda persona humana, otra definir en abstracto qué se entiende por justicia, y otra acordar por unanimidad qué es justo aquí y ahora. Me parece que la dificultad [...] no debería oscurecer la evidencia de ese sentido de justicia del que todo nace y que es percibido por cada uno de nosotros como valor absoluto, no negociable".

Zagrebelsky: "Usted destaca la condición común de todo ser humano en la apertura al sentido de la justicia, en el hambre y la sed de justicia. [...] Agregaría que una sociedad en la que esté agotado el sentido de la justicia, en la que no se lo pueda cultivar, es una sociedad deshumanizada en la que no vale la pena vivir"38.

Picó i Junoy considera que uno de los fenómenos más relevantes del Derecho Procesal que se ha desarrollado durante el siglo XX ha sido el de la "publicización" o "socialización" del proceso. Entiende que ha quedado de manifiesto la distinción entre el concepto de objeto del proceso y el concepto de proceso como instrumento idóneo para alcanzar la efectiva tutela. Si bien

36 Couture, E. (2016). Ob. cit., 181, 184 y 186.

37 Oteiza, E. (2017). "Eduardo J. Couture. Huellas que ayudan a comprender el presente”. En Á. Landoni Sosa y S. Pereira Campos. Estudios de Derecho Procesal en homenaje a Eduardo J. Couture. Tomo I. Montevideo. La Ley, 21.

38 Zagrebelsky, G. y Martini, C. M. (2006). La exigencia de justicia. Madrid. Trotta, 66-67. 
los litigantes son libres de disponer de los intereses deducidos en juicio, 0 sea, del objeto del proceso, no lo son respecto del proceso mismo, al concebirse no solo como instrumento dirigido a la tutela jurisdiccional de Derechos Privados, sino además como medio para cumplir una función pública del Estado. Y más precisamente deja de aceptarse como válida una solución cualquiera del conflicto para reconocer la necesidad de arribar a una solución justa ${ }^{39}$.

Por otro lado, Carretta Muñoz afirma que el proceso requiere de una directriz ética que le sirva de guía y, consecuentemente, los deberes jurídicos procesales buscan, más allá del desarrollo del proceso, que este se desenvuelva de una manera éticamente correcta. Ello por cuanto los deberes emanan del estadio axiológico del proceso ${ }^{40}$.

En Latinoamérica, Londoño advierte que la concepción actual del Estado impacta en la forma de practicar el Derecho, el proceso adquiere una nueva perspectiva en la que busca la solución justa del conflicto jurídico. Así, se espera el cumplimiento de determinados deberes de las partes vinculados a colaborar con el buen funcionamiento de la administración de justicia ${ }^{41}$.

La exigencia de debido proceso se manifiesta en dos dimensiones: una adjetiva o formal y otra sustantiva o material. Por un lado, la faceta formal alude al cumplimiento de ciertos recaudos formales, de trámite y de procedimiento, es decir, el conjunto de reglas procesales de carácter obligatorio -de orden público- que regulan un procedimiento para que sea este formalmente válido ${ }^{42}$.

Entendemos que es en este marco en que corresponde analizar el proceso uruguayo. La Constitución garantiza el debido proceso en sus dos dimensiones y ello impone, consecuentemente, un modelo procesal basado en garantías efectivas para la protección de los derechos ${ }^{43}$.

39 Picó i Junoy, J. (2012). Ob. cit., 50-56.

40 Carretta Muñoz, F. (2008). "Deberes procesales en el proceso civil chileno: referencia a la buena fe procesal y al deber de coherencia”. Revista de Derecho, Vol. XXI, 116 y 123.

41 Londoño Jaramillo, M. (2007). "Deberes y derechos en el Estado social de Derecho. Opinión Jurídica, Vol. 6, Nro. 11, 67-86.

$42 \mathrm{El}$ debido proceso formal como garantía se consagra en la Declaración Universal de Derechos Humanos (DUDH), artículos 81, 11; Pacto Internacional de Derechos Civiles y Políti$\cos$ (PIDCP), artículos $2^{\circ}, 9^{\circ}$ y 14; Declaración Americana de los Derechos y Deberes del Hombre (DADyDH), artículos 18 y 26. Sobre las dimensiones del debido proceso, cfr. Ticona Postigo, V. (2007). "El debido proceso y las líneas cardinales para un modelo procesal en el Estado constitucional de Derecho". Revista Oficial del Poder Judicial de Perú, Nro. 1/2, 27-49. Gozaíni, O. (2017). El debido proceso. Estándares de la Corte Interamericana de Derechos Humanos. Tomo I. Buenos Aires. Rubinzal-Culzoni, 23-35.

43 Cfr. Risso Ferrand, M. (2011). Algunas garantías básicas de los Derechos Humanos. Montevideo. Universidad Católica del Uruguay y (2005). Derecho Constitucional. Tomo 1. Montevideo. Fundación de Cultura Universitaria. Barnech Cuervo, M. C. (2016). El juez como 
Como se explicó en el apartado "Deber de veracidad en el sistema procesal civil uruguayo", este se consagra expresamente en los artículos $5^{\circ}$ y 63 , con remisión al artículo 142 . Sin perjuicio, entendemos que este deber se ve reforzado desde una interpretación integral del sistema procesal. Son varias las disposiciones del CGP que se alinean en el mismo sentido.

El artículo 11 incorpora expresamente el derecho a la tutela jurisdiccional efectiva, con lo que ello implica; y, por su parte, el artículo 14 reconoce como criterio interpretativo de la norma procesal que el fin del proceso es la efectividad de los derechos sustanciales y la defensa del debido proceso.

Puede advertirse, también, un cúmulo de disposiciones que conforman una regulación unitaria de la conducta procesal de las partes con consecuentes sanciones en caso de incumplimiento, como, por ejemplo, los artículos 56, 57 y $61^{44}$. Asimismo, corresponde recordar el instituto de la declaración de parte, la forma y el contenido de los actos de proposición ${ }^{45}$.

A ello se agregan las facultades, los poderes y los deberes del tribunal para sancionar conductas indebidas. Pero lo más destacable es el artículo 24, que faculta al tribunal a ordenar las diligencias necesarias para el esclarecimiento de la verdad de los hechos controvertidos, respetando el derecho de defensa de las partes. Y, aún más, en el artículo 25 se le impone al tribunal el deber de averiguar la verdad de los hechos alegados por las partes; la omisión en el cumplimiento de estos deberes le hará incurrir en responsabilidad.

Ante estas disposiciones, Pereira Campos entiende que el proceso uruguayo ha ido alejándose de la clásica y liberal postura antagónica entre partes para buscar una visión más publicista en la forma de administrar justicia, lo que es coincidente con los criterios propuestos por el Código Pro-

garante último de la protección de los Derechos Humanos. Panorama desde la acción de amparo y la problemática de los medicamentos de alto costo [tesis aprobada para adquirir la titulación de Magíster en Derecho Constitucional, con énfasis en Derechos Humanos, Universidad Católica del Uruguay].

44 Cfme. Cal Laggiard, M. (2013). Ob. cit., 24, 27.

45 Artículos 117-122, 130-136 y 148-153 del CGP. El artículo 117 dispone, entre los requisitos de la demanda: "[...] la narración precisa de los hechos" (teoría de la sustanciación y exigencia de clare loqui). El artículo 130, entre los requisitos de la contestación, dispone: “[...] el demandado deberá pronunciarse categóricamente sobre la veracidad de los hechos alegados en la demanda". Cfr. Klett, S.; Baluga, C.; Elizalde, L.; Dávila, J. y Soñora, G. (2002). "El principio de lealtad en los actos de proposición y en la audiencia preliminar". En XVIII Jornadas Iberoamericanas y XI Uruguayas de Derecho Procesal. Montevideo. Fundación de Cultura Universitaria, 93-123. Baluga, C. (2015). "La aplicación del principio de buena fe en la audiencia preliminar". En XVII Jornadas Nacionales de Derecho Procesal. Montevideo. Fundación de Cultura Universitaria, 19-32. 
cesal Modelo para Iberoamérica (CPMI), en cuanto a que el fin del proceso es la efectividad de los derechos sustanciales ${ }^{46}$.

Ordoqui Castilla, al analizar esta regulación procesal uruguaya, entiende que el proceso está ordenado en función de una conducta ética que deben seguir los sujetos intervinientes, por lo que todas las normas procesales confluyen en un fin común que es el arribar a la verdad y la justicia ${ }^{47}$.

En síntesis, podemos aseverar que se ha demostrado (muy brevemente y con "pinceladas") que la consagración legal del deber de veracidad resulta no solo una opción legislativa formalmente legítima, sino también coherente y consistente con todo el sistema procesal uruguayo en su conjunto: buena fe, lealtad y colaboración son su eje articulador; debido proceso y tutela jurisdiccional efectiva.

\section{La veracidad, ¿requiere necesariamente su consagración legal explícita, o, por el contrario, se impone, en el proceso civil, aun en ausencia de ella?}

"Parece empresa descabellada fundar la ética solo sobre sí misma,
sin referencia o conexión a un horizonte global
y, por lo tanto, al tema de la verdad.
Pero ícuál es la esencia de la verdad?
Pilato hizo a Jesús esa pregunta, pero no esperó su respuesta,
porque tenía prisa y quizá también porque no estaba
realmente interesado en el problema. La cuestión de la ética está unida al problema de la verdad [...]”38.

Hasta aquí hemos intentado justificar la legítima consagración explícita jurídico-procesal del deber de veracidad de las partes en el sistema procesal civil uruguayo.

Ahora bien, si el sistema no consagrara tal imposición, ¿se impondría igualmente un deber de ser veraz en el proceso civil?

Esta pregunta da cuenta de algunos desafíos y complejidades que enfrenta el Derecho Procesal. Por un lado, debe afrontar la dificultad de que el proceso garantice los intereses de los individuos que participan de él y,

46 Pereira Campos, S. (2012). "Algunas lecciones aprendidas en la aplicación del Código Procesal Modelo para Iberoamérica en Uruguay". Derecho \& Sociedad, Nro. 38, 300 y especialmente sobre deber de veracidad, 303.

47 Ordoqui Castilla, G. (2009). Ob. cit., 567-582.

48 Eco, H. y Martini, C. M. (1997). ¿En qué creen los que no creen? Madrid. Planeta, 163. 
además, responda con soluciones socialmente aceptables en beneficio del interés común.

Por otro lado, pone de manifiesto la íntima y cada vez más creciente relación entre el Derecho Procesal y la Filosofía del Derecho que, históricamente, ha sufrido acercamientos y desencuentros. Se reconoce una larga tradición en que el Derecho Procesal se ha reducido a una perspectiva formalista procedimental.

Probablemente el acercamiento se ha producido a lo largo del tiempo, más específicamente en torno a la actividad del juez y el razonamiento judicial o sobre las teorías acerca de la construcción de la decisión, donde puede reconocerse con mayor claridad un diálogo entre ambos puntos de vista. Sin embargo, la reflexión acerca de la posición de las partes no ha tenido el mismo desarrollo y es más reciente ${ }^{49}$.

En efecto, para comprender la temática de la veracidad como objeto de estudio y redimensionar su alcance en el proceso, debemos alejarnos de la mirada formalista del Derecho Procesal (sin desconocer la construcción sobre la teoría general del proceso), para dar paso a otra, donde este se enmarca dentro de una teoría del Derecho y, más específicamente, desde la filosofía ${ }^{50}$.

Justamente, la tríada -cada vez más pujante- "hechos, prueba y verdad", donde se ubicaría la veracidad como deber, ha exigido un abordaje filosófico-epistémico ${ }^{51}$.

49 "El estudio de la prueba de los hechos, la valoración racional de la prueba, la motivación racional y la búsqueda de la verdad en el proceso han sido objeto de atención por parte de los iusfilósofos en las últimas décadas, dando lugar a un renovado estudio epistemológico por parte de la Teoría del Derecho y de la Filosofía del Derecho sobre otras disciplinas, siendo principalmente una de ellas el Derecho Procesal: la verdad como condición de justicia, la estructura dialéctica del proceso, como encuentro entre las partes y diálogo del juez en su razonamiento, la relevancia del lenguaje en el proceso, y tantas otras cuestiones constituyen áreas de interés por parte de ambas disciplinas". Belloso Martín, N. (2020). "Algunos retos para la filosofía jurídica actual: las posibilidades de una filosofía del derecho procesal constitucional". Revista Eletrônica da Faculdade de Direito de Campos, Vol. 5, Nros. 1, 85-112.

50 Cfr. Meroi, A. (2007). "El Derecho Procesal y las ramas del mundo jurídico". Investigación y Docencia, Nro. 40, 165-175.

51 "Desde las primeras páginas de este documento declaramos nuestra intención de reflexionar sobre la experiencia procesal yendo más allá de los mecanismos conocidos que ofrece el positivismo lógico-formal y el racionalismo de la Ilustración, deteniéndonos en el papel de los seres humanos en el proceso, en la creencia de que una aproximación filosófica al proceso que aspira a aparecer creíble y bien fundada no puede permanecer anclada en categorías formales y abstractas que, aunque bien conocidas, deberían conceder espacios adecuados para cuestionar el papel de los individuos, sus historias, su cultura, el significado de sus acciones dentro del contexto social de origen, primero, y en el procesal, después”. Di Donato, F. y Scamardella, F. (2015). "Filosofía y Derecho Procesal: las nuevas fronteras del Derecho contemporáneo. Voces en acción”. Enciclopedia de Filosofía y Teoría del Derecho, Vol. 3, 2143-2193. Cfr. también 
Ello se reafirma con la constatación de que la sociedad contemporánea con sus demandas, contradicciones y aporías nos interpela y nos embiste. Actualmente, prácticamente sin importar desde qué enfoque jurídico-filosófico se parta, es insoslayable desconocer el vacío de la sociedad actual. Desde la claridad y, a veces, crudeza de Bandieri, "atravesamos una crisis que, como su etimología señala, marca incertidumbre en el juicio y en la decisión, cuando no sabemos bien qué hacer porque no sabemos bien qué pensar, ya que están afectadas -como señalaba en su tiempo Ortega y Gasset- no tanto las ideas que tenemos, sino las creencias mismas que somos" 52 .

Si bien no corresponde plantear la problemática casi irresoluta entre el Derecho y la moral, podemos destacar la visión de Méndez, para quien el Derecho, aunque no recoja todo lo moral, lo que recoge es una parte de la moral, en tanto lo jurídico puede no totalizar la vida humana, pero tiende a asegurar las condiciones y el clima social que hagan posible su integral desarrollo ${ }^{53}$.

Se comparta o no esta interrelación, sí parece indiscutible, como explica Portela, que lo propio y significativo del Derecho es la alteridad: la conducta de uno refiere siempre a otro. De esta forma, definitivamente se trata de preferir valores que se relacionan con esa dimensión ad alterum, denominados "valores de conducta bilateral" 44 .

posturas acerca de una posible "Filosofía del Derecho Procesal". Agudelo Ramírez, M. (2006). Filosofía del Derecho Procesal. Bogotá. Leyer.

52 Bandieri, L. M. (s. f.). ¿Un neopositivismo moral?

53 "Ciertamente el Derecho recoge una minima moralia, pero no establece un contenido extra moralia (fuera de la moral). Los contenidos jurídicos, aunque no recojan todo lo moral, lo que recogen es una parte de la moral y, como tal parte, intrínsecamente sigue perteneciendo al todo de la moralidad de la vida humana. Lo jurídico no totaliza la vida humana, no comprehende unitariamente todos sus aspectos, pero tiene en su finalidad asegurar las condiciones y el clima social que hagan posible el desarrollo de esa totalidad en perspectiva del sentido de la vida. [...] Lo jurídico no se cierra sobre sí mismo, sino que mantiene su pertenencia al todo, a la plenitud moral, que es la plenitud de la persona. La minima moralia es jurídicamente exigible, pero la maxima moralia es política, cultural y religiosamente ofertable”. Méndez, J. R. (2017). “Derecho y moral. ¿Por qué ocuparnos? ¿De qué ocuparnos?”. Prudentia Iuris, Nro. 84, 19-29. Cfr. también: "[...] lo jurídico nunca puede ser considerado desvinculado de la moral, porque la actividad humana libre es estudiada principalmente por la filosofía moral. No estoy diciendo que el Derecho y la moral sean lo mismo, solo digo que pertenecen al mismo orden de cosas, que es la conducta humana libre". Maino, G. (2018). "Billy Budd o sobre la existencia del Derecho Natural". Prudentia Iuris, Nro. 86, 21-34.

54 "Pero hay más, lo propio y característico del Derecho es la alteridad, a partir de la cual mi conducta se refiere siempre a otro: ad alterum. [...] Entendemos que con la expresión 'valores de conducta bilateral' se alude, como expresáramos más arriba, a todos aquellos valores que tienen que ver con la dimensión de alteridad en cuanto esta tiene de jurídica [...]”. Portela, J. (2008). Una introducción a los valores jurídicos. Buenos Aires. Rubinzal-Culzoni, 62. Cfr. también: Maino, G. (2012). "Derechos Humanos y consenso o el eterno retorno del positivismo jurídico". Prudentia Iuris, Nro. 73, 13-32. 


\section{CECILIA BARNECH CUERVO}

En esta alteridad o intersubjetividad propia del Derecho pueden concebirse los derechos, los deberes y las obligaciones. El Derecho es tal en función del otro, de su carácter de alteridad, y corresponde darle al deber -como conducta exigible- un lugar central. Bandieri reivindica los deberes como tales, advirtiendo que el Derecho se ha ocupado afanadamente por los derechos y no de igual forma por los deberes. "Es hora, quizás, de que los juristas volvamos sin complejos la mirada a los deberes" 55 .

Maino coincide en que los deberes son los "grandes ausentes de la organización jurídico-política occidental”, que revalorizar los deberes requiere revalorizar la alteridad, reconocer al otro como a quien se está obligado ${ }^{56}$.

Por su parte, Ettlin advierte, también, que es necesario poner en el debate jurídico la problemática de los deberes. Las reivindicaciones sobre los derechos, de alguna forma, han dejado de lado el debate sobre los deberes, olvidando que los derechos se conquistan asumiendo deberes ${ }^{57}$.

Así las cosas, consideramos que en la sociedad actual los deberes deben dar pelea y es en este contexto en el que debemos posicionar el proceso, la verdad y el rol de las partes.

Por otra parte, la verdad como única y cognoscible o alcanzable (presupuesto del que partimos) también resulta cuestionada ${ }^{58}$. Sin embargo, par-

55 Bandieri, L. M. (s. f.). Derechos fundamentales, ¿̇deberes fundamentales?; sobre el reconocimiento histórico de los deberes fundamentales y deberes jurídicos, Peces-Barba, G. (1987). "Los deberes fundamentales". DOXA. Cuadernos de Filosofía del Derecho, Nro. 4, 329341.

56 "Además de ese salir de nosotros mismos que requiere el reconocer al otro, entender lo jurídico desde el deber también se funda en el hecho de que el hombre, por el solo hecho de vivir, por más aislada y limitada que sea su actividad, se hace incesantemente deudor. [...] Para ello es necesario recuperar el horizonte de los deberes tanto desde el punto de vista social y político, como también desde el punto de vista jurídico". Maino, G. (2016). "Derechos fundamentales y la necesidad de recuperar los deberes. Aproximación a la luz del pensamiento de Francisco Puy". Derecho y cambio social, Vol. 13, Nro. 43, 1-27. Cfr. también: "Desde esta perspectiva, la dignidad adquiere toda su trascendencia jurídica al asumirse no solo en su sentido pasivo u 'ontológico', sino también desde su rol activo o moral, lo que significa que toda persona tiene la obligación o deber de comportarse conforme su constitutivo esencial humano para alcanzar la dignidad de su naturaleza, tanto en sí misma como frente a los demás”. Quintana, E. M. (2017). "Dignidad y deberes humanos". Prudentia Iuris, Nro. 83, 73-94.

57 "La armonía y la dinámica social requieren también la consideración de que los derechos existen pero se conquistan asumiendo deberes, y de que ambos no son excluyentes o diferentes; constituyen dos fuerzas que confluyen a la evolución progresista de las relaciones humanas". Ettlin, E. (2013). Hacia una teoría jurídica general sobre los deberes humanos.

58 Juan Pablo II advertía respecto de nuestras sociedades: "Pero, de este modo, ha desaparecido la necesaria exigencia de verdad en aras de un criterio de sinceridad, de autenticidad, de 'acuerdo con uno mismo', de tal forma que se ha llegado a una concepción radicalmente subjetivista del juicio moral [...]. Como se puede comprender inmediatamente, no es ajena a esta evolución la crisis en torno a la verdad". Carta encíclica Veritatis Splendor. 
timos de la afirmación de que el hombre tiende naturalmente a la verdad y, correlativamente, asume el deber de buscarla, en cuanto permite la interrelación social. Las relaciones humanas se basan en la confianza recíproca y esa es posible si se actúa en la verdad ${ }^{59}$.

Nada de ello debería ser ajeno al proceso jurisdiccional y, particularmente, el civil.

Pero para ello deben adoptarse algunas posturas de corte filosófico. Desde la perspectiva en la que nos hemos centrado, para fundar el deber de veracidad en el proceso civil, necesariamente debemos partir inicialmente desde el presupuesto gnoseológico de que la realidad es cognoscible y la verdad es alcanzable, como viene de justificarse.

No desconocemos que la tríada "hechos, prueba y verdad" ha sido objeto de desvelos de la dogmática. No pretendemos dar respuesta a este dilema, sino humildemente abordar la veracidad como deber impuesto a las partes en el proceso civil.

$\mathrm{Si}$, por un lado, el hombre tiende naturalmente a la verdad y esta es una virtud (o, por lo menos, una conducta humana deseable para facilitar la convivencia social) y, por otro lado, el Derecho tiene como rasgo propio la alteridad, cabe considerar que el proceso jurisdiccional debe tender a la verdad, como camino a la justicia, y ello se impone aún más en la sociedad contemporánea.

En la "embriaguez posmoderna" la verdad ha sido deconstruida, si no desconocida. Sin embargo, más allá de las dificultades teóricas, la verdad es objetiva, buena y digna de ser considerada y, procesalmente, la determinación de la verdad en el proceso es posible y necesaria ${ }^{60}$. Es más, Taruffo tam-

59 "Por esto, la convivencia civil solo puede juzgarse ordenada, fructífera y congruente con la dignidad humana si se funda en la verdad. Es una advertencia del apóstol san Pablo: 'Despojándonos de la mentira, hable cada uno verdad con su prójimo, pues que todos somos miembros unos de otros'. Esto ocurrirá, ciertamente, cuando cada cual reconozca, en la debida forma, los derechos que le son propios y los deberes que tiene para con los demás. [...] Virtudes morales y valores del espíritu. Todas estas cualidades deben ser consideradas insuficientes por completo para dar a las relaciones de la vida diaria un sentido más humano, ya que este sentido requiere necesariamente como fundamento la verdad; como medida, la justicia; como fuerza impulsora, la caridad; y como hábito normal, la libertad”. Carta encíclica Pacem in terris.

CIC 2467, CIC 2468, CIC 2469, CIC 2486 y CIC 2487. Cfr. también: Benedicto XVI, "Carta encíclica Caritas in veritate", numeral 3.

60 Desde su concepción epistémica del proceso, del rol de las "narraciones procesales" y aun sin reconocer la necesidad de veracidad de las partes, igualmente Taruffo reconoce la importancia ineludible de la verdad. Taruffo, M. (2019). "La decisione giusta". Revista ÍtaloEspañola de Derecho Procesal, Vol. 2, 1-2 y 8. Cfr. también Taruffo, M. (2010). Ob. cit., 134 y 137. Haack, S. (2016). "La justicia, la verdad y la prueba: no tan simple, después de todo". En J. Ferrer Beltrán y C. Vázquez (Coords.). Debatiendo con Taruffo. Madrid. Marcial Pons, 331-336. Cfr. también Di Donato, F. y Scamardella, F. (2015). "Filosofía y Derecho Procesal: las nuevas 
bién destaca la verdad como valor de carácter moral, político, epistemológico y jurídico; sería difícil admitir que un ordenamiento en que la administración de justicia pueda basarse en el error, o bien sea indiferente frente a una comprobación falsa o verdadera, sea un ordenamiento justo ${ }^{61}$.

Ello no significará que en el proceso siempre pueda alcanzarse la verdad en el caso; pero en términos de Peyrano, sí se debe procurar aproximarse a ella en forma limitada y selectiva. Es decir, una aproximación limitada supone comprender los propios límites de acceso y producción de prueba en el proceso; y la aproximación selectiva es la que se hace dentro de las posibilidades procedimentales y el carácter o la naturaleza del objeto del proceso $^{62}$.

Con estas consideraciones asumidas, resta ensayar una respuesta a la pregunta inicial: determinar si las partes quedan igualmente sometidas a un deber de veracidad si este no es consagrado explícitamente.

Creemos que el panorama expuesto permite sostener que, efectivamente, la veracidad sí es un deber de conducta humana, natural. Tender a la verdad y buscarla es lo propio del ser humano. Consecuentemente, honrarla también debe serlo. ¿Por qué excluir ello en el proceso civil? Entendemos que no es admisible excluir a ningún sujeto del proceso de esta realidad; ello sería retacear su naturaleza.

Si el Derecho implica alteridad y como personas participamos de una tendencia natural a la verdad (la honestidad abarca todas las conductas humanas, en todo momento, más allá de las circunstancias), entonces eso es aún más lógico en un proceso judicial que se abrogue de justo. Nada de ello debería entenderse como limitación o afectación de derechos (derecho de acción y defensa).

\footnotetext{
fronteras del Derecho contemporáneo. Voces en acción”. Enciclopedia de Filosofía y Teoría del Derecho, Vol. 3, 2143-2193. No desconocemos otras perspectivas desde las cuales la verdad no es relevante en el proceso. Cfr. Bandieri, L. M. (s. f.). Sobre la verdad en el Derecho y en el "Estado constitucional". La dogmática garantista, ya reseñada (ver apartado "La veracidad en la dogmática procesal civil”), tampoco reconoce la verdad como finalidad del proceso. Sobre otros cuestionamientos limítrofes, cfr.: Reyes, S. (2017). "Sobre Derecho y averiguación de la verdad". DOXA. Cuadernos de Filosofía del Derecho, Nro. 40, 317-337.

61 Taruffo, M. (2017). "Verdad y probabilidad en la prueba de los hechos". En Á. Landoni Sosa y S. Pereira Campos. Estudios de Derecho Procesal en homenaje a Eduardo J. Couture. Tomo I. Montevideo. La Ley, 145.

62 Cfr. Peyrano, J. W. (2017). "El juez y la búsqueda de la verdad en el proceso civil”. En Á. Landoni Sosa y S. Pereira Campos. Estudios de Derecho Procesal en homenaje a Eduardo J. Couture. Ob. cit., 158-161. Acerca de los límites y sus cuestionamientos a la aproximación a la verdad, cfr.: Nieva Fenoll, J. (2019). "La inexplicable persistencia de la valoración legal de la prueba". En G. Priori Posada. Justicia y proceso en el siglo XXI. Desafíos y tareas pendientes. Lima. Palestra, 334-353. Así como la problemática de la prueba ilícita.
} 
No se pretende elaborarlo como un deber absoluto de decir la verdad en el proceso, en el sentido más profundamente kantiano, pero sí proponer que entre un deber de transparencia tan inmenso como antinatural y un derecho desvergonzado a la mentira puede concebirse de alguna forma intermedia el deber procesal de veracidad ${ }^{63}$.

Gradi precisa que "l'obbligo di verità" solo puede entenderse con referencia al conocimiento personal de la parte, cuyas declaraciones pueden, por lo tanto, sin culpa, ser incorrectas o incompletas, pero no falsas o reticentes; parece posible superar los obstáculos informados en el nivel de la teoría general de procesos ${ }^{64}$.

Ello no importa una postura incrédula ante la posible conducta de las partes como sujetos interesados en el proceso. Reconocemos la complejidad de las alegaciones proposicionales iniciales. Empero ello no excluye la verdad ni permite la narración intencionalmente falaz. Podrá tratarse de una construcción lingüística interesada, modulada, si se quiere subjetiva. Aun puede concebirse como un discurso "estratégicamente organizado" 65 , pero no deliberadamente engañoso.

Así, tanto la palabra -como signo de racionalidad y fuerza perlocutiva- como los aspectos lingüístico-pragmáticos del discurso jurídico (en este caso de las partes) adquieren un lugar central. No se tratará de un discurso inocente, aséptico, sino, por el contrario, podrá entenderse cargado de connotaciones o estrategias discursivas enfocadas a la defensa de su postura, pero no significa que la mentira o deshonestidad, pues, vayan de suyo.

Desde esta perspectiva es que afirmamos que el deber de veracidad y el derecho de acción y defensa no son necesariamente contrapuestos o incompatibles.

Si revalorizamos los deberes como forma de protección de los derechos y entendemos la búsqueda de la verdad como inherente a la condición humana, entonces el deber de veracidad de las partes en el proceso -más allá de su consagración jurídica expresa- no solo no encontraría grandes objeciones, sino que aparecería como inexcusable.

\section{Síntesis final}

Primeramente, queremos expresar que en este esfuerzo de reflexión científica se intentó humildemente cumplir con la misión de todo integrante

63 Gradi, M. (2018). Ob. cit., XXXI (presentazione).

64 Gradi, M. (2009). "Il divieto di menzogna e di reticenza delle parti nel processo civile". Diritto e Formazione, año 3, Nro. 5, 794.

65 Aseff, L. M. (2003). Argumentación jurídica y semiosis social. Buenos Aires. Juris, 135. 
de una comunidad universitaria, académica: contribuir hacia una necesaria reflexión interpelante ${ }^{66}$.

Respecto del objetivo más particular de este trabajo, creemos que el reconocimiento expreso que el sistema procesal uruguayo da al deber de veracidad de las partes (como integrante de los principios de buena fe y colaboración procesal) ha quedado demostrado como legítimo, pertinente y consistente con el sistema procesal en general.

También consideramos que se ha echado luz sobre su relevancia y necesidad de revalorización a través de justificaciones jurídicas y filosóficas, más allá de su reconocimiento explícito legal. La veracidad y la imposición de deberes procesales juegan un papel central a la vez que controvertido. Sin perjuicio, el rol que la sociedad actual -voraz y vertiginosa- exige a los sistemas judiciales vuelve ineludible detenerse en su estudio, desde enfoques interrelacionados del Derecho Procesal y la Filosofía del Derecho ${ }^{67}$.

"[Un jurista], antes que nada, quiere y debe saber, igual que el hijo pródigo, quién es y cuál es su vocación y misión en este mundo. Y aun cuando sus contornos se presenten vagos e imprecisos, la idea de justicia no puede ser ajena a esa vocación, porque no es ajena a la idea de Derecho"68.

66 Sobre el rol de las universidades: "Esta enorme e impostergable tarea requiere, en el ámbito cultural de la formación académica y de la investigación científica, el compromiso generoso y convergente que lleve hacia un cambio radical de paradigma, más aún -me atrevo a decir- hacia 'una valiente revolución cultural'". Sumo pontífice papa Francisco, Constitución Apostólica Veritatis Gaudium.

67 Como se determinó inicialmente, por criterios metodológicos, no se abordó el rol del abogado en el cumplimiento de este deber por la parte. Indudablemente desempeña un papel protagónico en la elaboración de los actos de proposición iniciales o las denominadas narraciones alegacionales, donde las voces de la parte y del abogado prácticamente se funden. Ante ello -para finalizar el planteo y además intentar, humildemente, despertar y ampliar la reflexión-, dejamos planteada la interrogante acerca de cómo resuelve el abogado la tensión entre la veracidad y la defensa de su cliente o la denominada, por Taruffo, "ética de la narrativa del abogado". Creemos que, desde la perspectiva que propusimos en el presente, esta tensión sería más eventual y aparente que real. Una mirada estrictamente racional, o de lógica instrumental del Derecho Procesal, aparece como insuficiente y débil y, en consecuencia, el abogado, en resguardo de los deberes de la parte a quien asiste, debe desenvolverse en un sistema deontológico que fortalezca su desarrollo profesional ético. Cfr. Taruffo, M. (2007). "Narrativas judiciales". Revista de Derecho, Vol. XX, Nro. 1, 231-270. Gradi, M. (2012). "Etica della responsabilità: applicazioni e problemi. Sincerità dei litiganti ed etica della narrazione nel processo civile”. Lo Sguardo. Rivista di Filosofia, Nro. 8, 95-117. Véscovi, E. (Director) (1992). Código General del Proceso. Tomo I. Montevideo. Ábaco, 135. Malem, J. F. (2017). "Deontología profesional y la profesión de abogado”. DOXA. Cuadernos de Filosofía del Derecho, edición especial, 157. Santana Ramos, E. M. (2018). "El rol del abogado ante la ética y el ejercicio profesional". Revista de la Facultad de Derecho, Nro. 44, 9-18. De Zan, J. (2004). La ética, los derechos y la justicia. Montevideo. Konrad Adenauer Stiftung.

68 De Cores, C. (2019). "La interpretación del Derecho como vocación”. Revista de Derecho, Nro. 19, 157-180. 


\section{Fuentes y bibliografía}

\section{Fuentes}

Constitución (Uruguay).

Código General del Proceso (Uruguay).

Catecismo de la Iglesia Católica.

Cartas encíclicas Pacem in terris, Veritatis splendor, Caritas in veritate.

Constitución Apostólica Veritatis gaudium.

\section{Otras fuentes}

"Real Cédula de Erección del Consulado de Buenos Ayres expedida en Aranjuez a XXX de enero de MDCCXCI". Madrid. En la Oficina de Benito Cano, Ley V, 5 (https://sas-space.sas.ac.uk/7685/107/A00455.pdf).

Siete Partidas de Alfonso el Sabio (versión virtual Boletín Oficial del Estado. Gobierno de España) (https://www.boe.es/biblioteca_juridica/publicacion.php?id=PUBLH-2018-7\&tipo=L\&modo=).

\section{Bibliografía}

Abal Oliú, A. (2013). "El principio de buena fe procesal a partir del nuevo texto del art. $5^{\circ}$ del CGP". En CADE. Doctrina y Jurisprudencia, Nro. 24, 5-10.

Abal Oliú, A. (2014). "La verdad y el proceso jurisdiccional en Uruguay". En I Seminario Internacional de Derecho Procesal: Dilemas sobre la verdad en el proceso judicial (Colección de Investigaciones en Derecho, Nro. 2). Medellín. Universidad Pontificia Bolivariana, 187-223.

Agudelo Ramírez, M. (2006). Filosofía del Derecho Procesal. Bogotá. Leyer.

Alvarado Velloso, A. (2014). "La imparcialidad judicial y el debido proceso (la función del juez en el proceso civil)”. En Ratio Juris, Vol. 9, Nro. 18, 207-235.

Alvarado Velloso, A. y Valentín, G. (2011). Lecciones de Derecho Procesal Civil. Compendio del libro "Sistema procesal: Garantía de la libertad" adaptado a la legislación uruguaya. Montevideo. La Ley.

Arcaria, F. (2019). "Il 'dovere di verità'. Contributo alla comparazione tra la deontologia forense italiana e l'esperienza giuridica romana”. Teoria e Storia del Diritto Privato, Nro. XII, 1-100.

Aseff, L. M. (2003). Argumentación jurídica y semiosis social. Buenos Aires. Juris.

Balestro Faure, M. (2011). "El principio que prohíbe el abuso de los Derechos Procesales”. En J. W. Peyrano (Director), Principios procesales. Tomo I. Buenos Aires. Rubinzal-Culzoni.

Baluga Bello, C. (2015). "La aplicación del principio de buena fe en la audiencia preliminar". En XVII Jornadas Nacionales de Derecho Procesal. Montevideo. Fundación de Cultura Universitaria, 19-32. 


\section{CECILIA BARNECH CUERVO}

Bandieri, L. M. (s. f.). Derechos fundamentales, ¿deberes fundamentales? (https:// www.academia.edu/9075725/_Derechos_fudamentales_y_deberes_fundamentales, 8/2019).

Bandieri, L. M. (s. f.). Sobre la verdad en el Derecho y en el "Estado constitucional". (https://www.academia.edu/28372703/LA_VERDAD_DE_LOS_JUICIOS_Y_ LOS.pdf, 2/2020).

Bandieri, L. M. (s. f.). ¿Un neopositivismo moral? (https://www.academia. edu/14542487/_UN_NEOPOSITiVISMO_MORAL, 2/2020).

Baracat, E. J. (2011). “¿Otro principio procesal: ‘clare loqui’? La interpretación de los actos procesales. Voluntad declarada versus voluntad interna”. En J. W. Peyrano (Director). Principios procesales. Tomo II. Buenos Aires. Rubinzal-Culzoni.

Baracat, E. J. (2017). "El principio de colaboración procesal”. Revista da Esmal, Nro. 6, 95-104.

Barberio, S. y García Solá, M. (2011). "Lineamientos del principio de moralidad”. En J. W. Peyrano (Director). Principios procesales. Tomo I. Buenos Aires. RubinzalCulzoni.

Barnech Cuervo, M. C. (2016). El juez como garante último de la protección de los Derechos Humanos. Panorama desde la acción de amparo y la problemática de los medicamentos de alto costo [tesis aprobada para adquirir la titulación de Magíster en Derecho Constitucional. Universidad Católica del Uruguay]. (https:// liberi.ucu.edu.uy/xmlui/handle/10895/571, 4/2020).

Barnech Cuervo, M. C. (2019). Siete Partidas de Alfonso X: ¿Puede advertirse una exigencia de conducta proba para los sujetos intervinientes en el pleito en la regulación procesal de la Tercera Partida? [presentado en el marco del Doctorado en Ciencias Jurídicas, Universidad Católica Argentina].

Belloso Martín, N. (2020). “Algunos retos para la filosofía jurídica actual: las posibilidades de una filosofía del derecho procesal constitucional”. Revista Eletrônica da Faculdade de Direito de Campos, Vol. 5, Nro. 1, 85-112. (http://www.revistas. uniflu.edu.br:8088/seer/ojs3.0.2/index.php/direito/issue/view/8/14, 4/2020).

Cal Laggiard, M. (2013). "Primeras lecturas de la reforma del CGP". Revista de Derecho de la Universidad de Montevideo, Nro. 24, 23-81.

Calvinho, G. (2010). "Los Derechos Humanos en la teoría del proceso". En G. Águila Grados; A. Calderón Sumarriva; G. Calvinho y R. M. González. El Derecho Procesal del siglo XXI. Lima. San Marcos, 37-76.

Canteros, F. (2017). "La doctrina de los actos propios y la mala fe procesal". Revista da Esmal, Nro. 6, 95-104.

Caroni, P. (2014). La soledad del historiador del Derecho. Apuntes sobre la conveniencia de una disciplina diferente. Madrid. Dykinson.

Carratta, A. (2014). "Dovere di verità e completezza nel processo civile". Rivista Trimestrale di Diritto e Procedura Civile, Vol. 68, Nro. 2, 47-76.

Carretta Muñoz, F. (2008). "Deberes procesales en el proceso civil chileno: referencia a la buena fe procesal y al deber de coherencia”. Revista de Derecho, Vol. XXI, 101-127.

Cipriani, F. (2006). "El abogado y la verdad". En Montero, J. (Coord.). Proceso civil e ideología: un prefacio, una sentencia, dos cartas y quince ensayos. Valencia. Tirant Lo Blanch, 283-291. 
Cipriani, F. (2007). "El autoritarismo procesal (y las pruebas documentales)". Revista Ius et Praxis, año 13, Nro. 2, 44-55.

Coloma Correa, R. (2006). "Vamos a contar mentiras, tralará..., o de límites a los dichos de los abogados”. Revista de Derecho, Vol. XIX, Nro. 2, 27-52.

Couture, E. (2016). Estudios de Derecho Procesal Civil. Montevideo. La Ley.

De Cores, C. (2019). "La interpretación del Derecho como vocación". Revista de Derecho, Nro. 19, 157-180.

De Zan, J. (2004). La ética, los derechos y la justicia. Montevideo. Konrad Adenauer.

Di Donato, F. y Scamardella, F. (2015). "Filosofía y Derecho Procesal: las nuevas fronteras del Derecho contemporáneo. Voces en acción”. Enciclopedia de Filosofía y Teoría del Derecho, Vol. 3, 2143-2193.

Eco, H. y Martini, C. M. (1997). ¿En qué creen los que no creen? Madrid. Planeta.

Eguren, M. C. (2011). "El principio de eventualidad procesal: los alcances de una autocontradicción permitida”. En J. Peyrano (Director). Principios procesales. Tomo I. Buenos Aires. Rubinzal-Culzoni, 453-478.

Ettlin, E. (2013). Hacia una teoría jurídica general sobre los deberes humanos. (https://www.academia.edu/7410958/LOS_DEBERES_HUMANOS, 1/2020).

González Salzberg, D. (2008). "El derecho a la verdad en situaciones de postconflicto bélico de carácter no internacional”. International Law: Revista Colombiana de Derecho Internacional, Nro. 12, 436-467.

González, R. M. (2010). "Proceso, república y democracia: algunas claves para constitucionalizar el proceso”. En G. Águila Grados; A. Calderón Sumarriva; G. Calvinho y R. M. González. El Derecho Procesal del siglo XXI. Lima. San Marcos, 77-116.

Gozaíni, O. (2017). "El deber de decir verdad en el pensamiento de Couture”. En Á. Landoni Sosa y S. Pereira Campos. Estudios de Derecho Procesal en homenaje a Eduardo J. Couture. Tomo I. Montevideo. La Ley, 183-219.

Gozaíni, O. (2017). El debido proceso. Estándares de la Corte Interamericana de Derechos Humanos. Tomo I. Buenos Aires. Rubinzal-Culzoni.

Gradi, M. (2009). "Il divieto di menzogna e di reticenza delle parti nel processo civile". Diritto e Formazione, año 3, Nro. 5, 793-798.

Gradi, M. (2012). "Etica della responsabilità: applicazioni e problemi. Sincerità dei litiganti ed etica della narrazione nel processo civile". Lo Sguardo. Rivista di Filosofia, Nro. 8, 95- 117.

Gradi, M. (2015). "Omessa indicazione di fatti decisivi e violazione dell'obbligo di lealtà processuale”. Il Foro Italiano, Vol. III, 3-18.

Gradi, M. (2018). L'obbligo di verità delle parti. Torino, G. Giappichelli Editore.

Haack, S. (2016). "La justicia, la verdad y la prueba: no tan simple, después de todo". En J. Ferrer Beltrán y C. Vázquez (Coords.). Debatiendo con Taruffo. Madrid. Marcial Pons, 311-336.

Heñin, F. A. (2011). "El principio de moralidad en el proceso civil”. En J. W. Peyrano (Director). Principios procesales. Tomo I. Buenos Aires. Rubinzal-Culzoni.

Klett, S; Baluga, C.; Elizalde, L.; Dávila, J. y Sóñora, G. (2002). "El principio de lealtad en los actos de proposición y en la audiencia preliminar". En XVIII Jornadas Iberoamericanas y XI Uruguayas de Derecho Procesal. Montevideo. Fundación de Cultura Universitaria, 93-123. 


\section{CECILIA BARNECH CUERVO}

Landoni, Á. (2014). "Las modificaciones introducidas al Código General del Proceso por la Ley $\mathrm{N}^{\text {o }}$ 19.090. Sentido general de la reforma”. En Curso sobre la reforma del Código General del Proceso (Ley No 19.090). Montevideo. La Ley.

Landoni, Á. (director) (2002). Código General del Proceso comentado, anotado, con jurisprudencia, Vol. 1. Montevideo. BdeF.

Londoño Jaramillo, M. (2007). "Deberes y Derechos Procesales en el Estado social de Derecho”. En Opinión Jurídica, Vol. 6, Nro. 11, 67-86.

López Flores, L. (2016). “Los 'Poderes Judiciales', proceso y política judicial: una mirada desde el Estado constitucional”. En Revista de la Maestría en Derecho Procesal, Vol. 6, Nro. 2, 146 -178.

Maino, G. (2012). "Derechos Humanos y consenso o el eterno retorno del positivismo jurídico”. Prudentia Iuris, Nro. 73, 13-32.

Maino, G. (2016). "Derechos fundamentales y la necesidad de recuperar los deberes. Aproximación a la luz del pensamiento de Francisco Puy". En Derecho y Cambio Social, Vol. 13, Nro. 43, 1-27.

Maino, G. (2018). "Billy Budd o sobre la existencia del Derecho Natural”. En Prudentia Iuris, Nro. 86, 21-34.

Malem, J. F. (2017). "Deontología profesional y la profesión de abogado". En DOXA. Cuadernos de Filosofía del Derecho, edición especial, 153-157.

Méndez, J. R. (2017). “Derecho y moral. ¿Por qué ocuparnos? ¿De qué ocuparnos?”. En Prudentia Iuris, Nro. 84, 19-29.

Meroi, A. (2007). "El Derecho Procesal y las ramas del mundo jurídico". En Investigación y Docencia, Nro. 40, 165-175.

Montero Aroca, J. (Coordinador) (2006). Proceso civil e ideología: un prefacio, una sentencia, dos cartas y quince ensayos. Valencia. Tirant Lo Blanch.

Nieva Fenoll, J. (2019). "La inexplicable persistencia de la valoración legal de la prueba”. En Justicia y proceso en el siglo XXI. Desafíos y tareas pendientes. Lima. Palestra, 334-353.

Ordoqui Castilla, G. (2009). Abuso de Derecho. En civil, comercial, procesal, laboral y administrativo. Montevideo. Universidad Católica del Uruguay.

Oteiza, E. (2017). "Eduardo J. Couture. Huellas que ayudan a comprender el presente”. En Á. Landoni Sosa y S. Pereira Campos. Estudios de Derecho Procesal en homenaje a Eduardo J. Couture. Tomo I. Montevideo. La Ley, 11-21.

Peces-Barba, G. (1987). "Los deberes fundamentales". En DOXA. Cuadernos de Filosofía del Derecho, Nro. 4, 329-341.

Pereira Campos, S. (2009). "Los procesos civiles por audiencias en Uruguay. 20 años de aplicación exitosa del Código Procesal Civil Modelo para Iberoamérica”. Revista Internacional de Estudios de Derecho Procesal y Arbitraje, Nro. 2.

Pereira Campos, S. (2011). "Moralidad, veracidad y colaboración: su incidencia en el proceso civil contemporáneo. El Código Procesal Civil Modelo para Iberoamérica y la experiencia de Código General del Proceso uruguayo". En Modernización de la justicia civil, 406-446.

Pereira Campos, S. (2012). "Algunas lecciones aprendidas en la aplicación del Código Procesal Modelo para Iberoamérica en Uruguay”. En Derecho \& Sociedad, Nro. $38,297-315$. 
Pereira Campos, S. (2013). "La reforma de la justicia civil en América Latina: una política pública ineludible”. En Derecho \& Sociedad, Nro. 41, 251-256.

Peyrano, J. W. (2006). "El abuso procesal recursivo o situación de recurso ad infinitum”. Ius et Veritas, Nro. 33.

Peyrano, J. W. (2010). “Acerca de los 'ismos' en materia procesal civil”. THËMISRevista de Derecho, Nro. 58, 23-27.

Peyrano, J. W. (2011). "El cambio de paradigmas en materia procesal civil". En J. W. Peyrano (Director). Principios procesales. Buenos Aires. Rubinzal-Culzoni, 131139.

Peyrano, J. W. (2017). "El juez y la búsqueda de la verdad en el proceso civil”. En Á. Landoni Sosa y S. Pereira Campos. Estudios de Derecho Procesal en homenaje a Eduardo J. Couture. Tomo I. Montevideo. La Ley, 158-161.

Picó i Junoy, J. (2002). "Los principios del nuevo proceso civil español”. XVIII Jornadas Iberoamericanas de Derecho Procesal, Jornadas Uruguayas de Derecho Procesal: en homenaje a la escuela procesalista uruguaya. Montevideo. Fundación de Cultura Universitaria.

Picó i Junoy, J. (2012). "El Derecho Procesal entre el garantismo y la eficacia: un debate mal planteado". Urbe et Ius: Revista de Opinión Jurídica, Nro. 38, 50-56.

Picó i Junoy, J. (2013). El principio de la buena fe procesal. Madrid. José María Bosch Editor.

Portela, J. (2008). Una introducción a los valores jurídicos. Buenos Aires. RubinzalCulzoni.

Quintana, E. M. (2017). “Dignidad y deberes humanos”. Prudentia Iuris, Nro. 83, 73-94.

Ramírez Carvajal, D. M. (2013). “Contornos del Derecho Procesal contemporáneo: luces desde la obra de Michele Taruffo". Revista Academia \& Derecho, Vol. 4, Nro. 7, 171-188.

Reyes, S. (2017). “Sobre derecho y averiguación de la verdad”. DOXA. Cuadernos de Filosofía del Derecho, Nro. 40, 317-337.

Risso Ferrand, M. (2005), Derecho Constitucional. Tomo 1. Montevideo. Fundación de Cultura Universitaria.

Risso Ferrand, M. (2011). Algunas garantías básicas de los Derechos Humanos. Montevideo. Universidad Católica del Uruguay.

Santana Ramos, E. M. (2018). "El rol del abogado ante la ética y el ejercicio profesional”. En Revista de la Facultad de Derecho, UDELAR, Nro. 44, 9-18.

Savater, F. (2004). Los diez mandamientos en el siglo XXI. Tradición y actualidad del legado de Moisés. Barcelona. Random House Mondadori.

Simon Caureo, E. (2017). "Introduzione al dovere di verità e completezza nel processo civile”. En Grisi, G. y Salvi, C. (Eds.), A propósito del diritto post-moderno. Atti Seminario Leonessa. Roma. Roma TrE-Press, 91-104.

Simon Caureo, E. (2018). "Il dovere di verità e completezza nel processo civile (Duty of Truthful Disclosure and Duty of Completeness in civil procedure, traducción libre)". En Civil Procedure Review, Vol. 9, Nro. 1, 27-42.

Simón, L. M. y Olivera, G. (2017). "Los deberes de colaboración y veracidad en el Código General del Proceso”. En Á. Landoni Sosa y S. Pereira Campos. Estudios 


\section{CECILIA BARNECH CUERVO}

de Derecho Procesal en homenaje a Eduardo J. Couture. Tomo I. Montevideo. La Ley, 293-314.

Taruffo, M. (2007). "Narrativas judiciales". Revista de Derecho. Valdivia, Vol. XX, Nro. 1, 231-270.

Taruffo, M. (2010). Simplemente la verdad. El juez y la construcción de los hechos. Madrid. Marcial Pons.

Taruffo, M. (2013). "Verdad, prueba y motivación en la decisión sobre los hechos". En Cuadernos de Divulgación de la Justicia Electoral, Nro. 20.

Taruffo, M. (2017). "Verdad y probabilidad en la prueba de los hechos". En Á. Landoni Sosa y S. Pereira Campos. Estudios de Derecho Procesal en homenaje a Eduardo J. Couture. Tomo I. Montevideo. La Ley, 133-161.

Taruffo, M. (2018). "Proceso y verdad en la transición”. En Derecho \& Sociedad, Nro. 50, 295-306.

Taruffo, M. (2019). "La decisione giusta". Revista Ítalo-Española de Derecho Procesal, Vol. 2, 1-8.

Taruffo, M. (2016). “Abuso del proceso”. En Revista de la Maestría en Derecho Procesal, Vol. 6, Nro. 2, 7-29.

Ticona Postigo, V. (2007). "El debido proceso y las líneas cardinales para un modelo procesal en el Estado constitucional de Derecho". En Revista Oficial del Poder Judicial de Perú, Nro. 1/2, 27-49.

Valentín, G. (2014). La reforma del Código General del Proceso. Montevideo. Fundación de Cultura Universitaria, 11-19.

Valiño Arcos, A. (2002). "Algunos aspectos relacionados con la imposición de costas en el proceso civil en el Derecho Comparado". En Revista Facultad de Derecho, Nro. 21, 251-257.

Van Rompaey, L. (1995). "La teoría de las cargas probatorias dinámicas en el Derecho Procesal uruguayo". En La Justicia Uruguaya. Tomo 111.

Véscovi, E. (Director) (1992). Código General del Proceso. Tomos I y II. Montevideo. Ábaco.

Zagrebelsky, G. (2009). El Derecho dúctil. Ley, derechos, justicia. Madrid. Trotta.

Zagrebelsky, G. y Martini, C. M. (2006). La exigencia de justicia. Madrid. Trotta. 